\title{
Discussion on Application and Aesthetic Appreciation of Graphics in Series Packaging Design
}

\author{
Jiayan Zheng \\ Yantai Nanshan University \\ Yantai, China
}

\begin{abstract}
The form of series packaging design appeared in the early 20th century. Later it becomes prevalent rapidly all over the world. The packaging design moves from single form towards serialization and rapidly gets development, which fully shows that this packaging form has met the needs of modern market competition. The series packaging design depends on visual characteristics of familization, uses packaging design elements to design consciously and takes it as the unified general characters to gain certain market. Graphics that reflect the visual characteristics of familization are very important technique of expression. This article mainly researches how to better use graphic design elements and aesthetic expression in series packaging design. Use the intuition, effectiveness, vitality and rich expressive force of graphics on visual communication to convey contents and information about commodities to consumers; depend on the attraction of graphics on vision to arouse psychic reaction of consumers and then guide purchasing behavior.
\end{abstract}

Keywords—packaging design; series; graphics application; aesthetic appreciation

\section{INTRODUCTION}

In modern consumer market, the goods shelves in supermarkets are the main places for consumers to buy goods. According to overseas investigative statistics, people often stay in supermarkets for about half an hours, while there are various goods and brands in supermarkets. How to arouse the impulse of consumers to buy goods? First of all, it is essential to strengthen the effects of visual impact of packaging. Then a kind of effective design method-- series packaging design that ensures eyes of consumers will not be attracted by the packaging of competitors and uses commodity groups as units rises in response to the proper time and conditions with the development of supermarket and purchasing habits of consumers. When designing, they should grasp the thick-and-thin common factors. That is to say, keep the consistency of trademark, font and representation style, at the same time, better use the design of elements of individuality. As important parts of packaging design elements, graphics always occupy a large proportion of the picture and become the important media to convey commodity information and stimulate consumers. Especially when it appears in series family forms, it is important about how to make packaging graphics have more individuality and aesthetic standards. Here, the author briefly gives opinions to discuss with you together.

\section{CONCEPT OF SERIES PACKAGING DESIGN AND SERIES OF RANGES}

Series packaging design refers to that for similar products in enterprises, take trademark as the principal part, and adopt common design for all goods governed by the same trademark in aspects such as image, color, pattern and words, to make them distinguished form goods of competitive enterprises. Series packaging is also called packaging of "familization". On serial combination of packaging, it requires the overall cooperation and organic unification of regular changes of details.

The basic principle of series packaging design is to make more than two kinds of commodity packaging design present unified stylistic form. Before designing, we should firstly clearly know the relationships between goods. It can help series design. As we all know, each commodity contains basic elements such as function, standard, quantity, constituent, modeling, color and price. If we classify these commodities according to some conditions, then we will be sure about what kind of goods are suitable for series packaging and we can bring what kind of good into the same scope to make series design. For the size of range, in the aspect of product elements, we can make integrated packaging design by basing on the quantity of product items in product line and listing products with the same or similar functions between product lines as the same series of range. To sum up, there are three division methods at least. We call them large series, medium series and small series.

- Large series: In the same brand, more than two kinds of packaging with the same style are called large series.

- Medium series: Goods of the same kind governed by the same trademark are classified into the same series because of similar property or function and this series is called medium series.

- Small series: Individual commodities with different model, taste and modeling can be regarded as a small series.

Series packaging is not simple and practicable on design. Same brand and unified graphics are not equal to successful packaging design. It emphasizes unified style and form and overall effect of packaging of different standards or different 
products visually, but not the repeated combination of packaging of same products with the same quantity and model. We must avoid by all means guiding the design with unified style to sameness. On the basis of understanding enterprise, knowing well about products and holding the market, according to different types, characteristics, functions, levels of products and consumption objects, we should reasonably combine products, divide series of scope and unify the style and tendency. Meanwhile, under the major premise of embodying the specific unified and symbolic visual characteristics of various commodity packaging in enterprises, it is necessary to manifest unique individuality of various goods and pursue changes in unification to achieve colorful effects of commodity packaging.

\section{APPLICATION OF SERIES PACKAGING DESIGN IN GRAPHICS}

Although the design of designers should rapidly tell the property of commodity concerned by consumers on packaging, it will lead to the differences of results because of different ways of telling. You can tell others there is a shirt inside the packaging, and you can also tell people this shirt is the ideal shirt exactly required by him. Obviously, using the expressional way of the latter on packaging has more appeal than the former. It requires us to concentrate our efforts on graphics on packaging. We should reasonably and effectively use the expression of design, design philosophy and technique of expression of graphics to form a complete visual figure to convey commodity information, and then attract consumers' interests in selecting and buying goods.

\section{A. Expression of Design:}

The key point is to confirm the main graphics of packaging. The specific methods include: take the image of commodity as subject image, namely reappear the commodity and then meet requirements of rational consumers; packaging design that takes brand, trademark and corporate logo as subject images always bases on the fact that the original brand, trademark or logo have already gained great popularity in market, and it is easy for them to be accepted by consumers if they further strengthen the design; packaging design that takes raw materials as subject image mainly focuses on highlighting the individual function of raw materials; take characteristics of commodity as subject image, such as for packaging of milk, emphasize its pure white and freshness; take unique color of commodity as subject image, such as the green color of tea, and brown color of chocolate; take products or place of origin of raw materials as subject images, and then meet curious and nostalgic psychological needs of consumers; take targetconsumer as subject image, to meet the requirements of consumers for appearance packaging and color with specific ideas in many specific time and situations, such as heartshaped packaging and the color of rose; take animals, plants, and flowers in daily life as subject images, to meet the requirements of consumers for nature, environmental protection and health; take special effect of words as subject image, to make consumers see clearly at a glance when purchasing and using commodities and improve the convenience; take specific shading texture or pattern as subject image to give people different artistic conception and feelings. If you want to return nature and have simple and unadorned, pure and mild feelings, we will give you the breath of soil, decorative pattern of trees, fragrance of flowers and grasses, flowing water in streams on graphics; if you are a little sad and sentimental, we will give you mist like gauze and transparent smell on graphics; if you have adventurous temperament and perseverance, we will give you graphics with metal luster on packaging. All in all, we should design according to properties of products.

\section{B. Technique of Expression}

After confirming main graphics of packaging, we should use appropriate technique expression. There are various techniques of expression, which can be roughly divided into material graph, abstract graph and decorative graph.

- Material graph is visualized and concrete objective image of product showed by techniques of photography and illustration. The technique of photography can directly apply true-life photos to packaging design and it can more directly convey commodity information; illustration mainly depends on freehand sketching. Compared with photography, it can surpass the limitations of photography. It is diversified and flexible and can freely accept or reject, extract, process and artfully exaggerate the graphics. This material graphics created by illustration have subjective and objective advantages.

- Abstract graph is the form created by generalizing and simplifying natural images, such as geometric shapes of point, line and face and irregular organic shapes. We can effectively divide the information on function of conveying. From the perspective of aesthetic appreciation, abstract graph is the formal expression with rich modern design ideas. Simple geometric shapes such as straight line, curve, rectangle and roundness are widely used in design because they conform to aesthetic preference of people for minimalist style.

- Decorative graph is the graph between material graph and abstract graph. It simplifies representational themes or makes modifying treatment to produce interestingness. It is a pattern of manifestation with great individuality, subjectively summarizes and describes natural shapes or objects. Decorative graph emphasizes complanation and conciseness and pays attention to organic relationships between black and white and the regularity on expression. It makes use of abstract graphics or decorative patterns to strengthen the sense of form of packaging to make commodity packaging become more unique.

\section{Design Philosophy}

When we confirm the main graphics and technique of expression of packaging and begin the series design, the design philosophy that we should follow is to keep integral 
visual unification. No matter adopting what kind of expression of design, when we present the series packaging designed by us in front of consumers, it must be a group of packaging with unified style. It demands variety in unity on design and achieves organic combination. Each graph should have characteristics and changes of its own. In aesthetic theory, change and unification are the general rules of formal beauty, which firstly emphasizes the diversified and integrated unification. There are traditions and achievements of integrated beauty in Chinese art and arts of the whole world. In all aspects of our life, people's pursuits for integrated beauty are penetrated and embodied everywhere. From furniture configuration to clothing design and from interior decoration to environmental art, all of them stress the integrated beauty of unified style.

\section{Aesthetic APPRECIATION OF GRAPHICS IN SERIES PACKAGING DESIGN}

In modern society, with continuous improvement of living standard, people's understandings for packaging are also deepened continuously. The feasibility of serialization of commodity packaging is that it can meet the increasingly high and renewed aesthetic standard and psychological needs of consumers. Let's talk about the color beauty and decorative beauty of graphics in series packaging design.

\section{A. Color Beauty}

The design of series of cosmetics uses the most delicate color beauty, such as the packaging of "CRISFERE" series of cosmetics. The graphic pattern is constituted by designers to interlace jewelry blue, white and silver and produce overlapped effects, bright and clear and decent. No wonder it is adored by vast consumers. Besides, the packaging of "Ruffles" series of cosmetics in America uses very few several strokes with characteristics of watercolor. Vibrant colors such as pink, pale green and light blue softly infiltrate, just as splendid as rosy clouds and it echoes with the heartshaped pattern on the white ground below. How fresh and romantic it is!

It gives people the strongest visual impact to use different saturated and bright colors. Many designers use them to show distinct features of products. It is pursued by energetic people with an outburst of enthusiasm. When we talk about persons who successfully use lively bright colors, we have to mention Chinese American Ms. Jin Yuxi. The "Yue-Sai" series of cosmetics operated by her have very good sales, not only because the cosmetics have good qualities that are suitable for people in the east, the rich and gaudy colors play an important role in it as well. In series of packaging of it, it adopts color matching such as dignified black and red, black and white as well as yellow and blue. In several series of it, black is the essential color all the time. It covers not a large area, but it's just perfect. Black is a mysterious and sedate color. Matching with red that is deeply loved by easterner especially Chinese people, it undoubtedly makes red become more beautiful and splendor; matching with bright colors such as white, it not only shows different functions (such as the packaging of sun block series chooses black to match with yellow) of different series and makes these bright colors more eye-dazzling, but also plays the function of unifying the color of the whole series. There is no doubt that these beautiful colors make products better show their nobility.

\section{B. Decorative Beauty}

Decorative beauty is mainly used in the design of graphics and utilization of materials in packaging design. It pays attention to the visual sense of rhythm and gives people eyeable aesthetic perception. It can be graphics combined by abstract point, line and face as well as pattern and texture, and refer to tradition. For example, decorate traditional pattern, auspicious pattern and folk pattern on the packaging of traditional commodities, native products and stationary commodities to effectively highlight cultural characteristics and national regional features of products. Using abstract graphics on modern commodity packaging helps to strengthen modern sense and fashionable feeling. In the process of long-term cultural development, together with people of all ethnic groups in the world, Chinese people have created colorful graphics with strong national features.

The packaging of "CHAMPAGNF" brand of perfume in France is one of the models. On the visual design of external packing of its carton, it adopts a large area of metal concavoconvex texture on the perfume bottle to produce fantastic texture patterns, which make exterior and interior packing have delicate relationships, elegant and noble. In China, rubbing stone texture of portrayals and eaves tile texture also give people the effects of visual texture. And quite a few textures are also skillfully applied to the series packaging of tea and tourism products. Besides, there are also many packaging that totally adopts touchable texture patterns to make the materials show natural beauty.

Series packaging design has become the design with the most market awareness in the whole packaging design field. The creation of expressional language is definitely not simple permutation and combination of visual elements, but creative activity that establishes on deeper level of research on people's psychological activity and profound understanding of purpose and significance of design. These activities should focus on innovation. Only new originality, new style and new technique of expression can attract people's attention and have distinctive psychological persuasion. Deepening the scope of visual communication and impact of packaging decoration, combining fine quality of products and shaping famous-brand products can bring boundless economic value for enterprises.

\section{CONCLUSION}

In conclusion, on design requirements of protection, convenience and aesthetic function, series packaging design is not different from basic principles of other commodity packaging. The differences mainly lie in highlighting the visual characteristics of serialization of packaging. We should research, analyze and explore, manifest relationships between forms and methods between characteristics of commodity, meet the requirements of development of commodity competition in modern market. In the tide of market economy, we should continuously meet the demands 
of enterprises for market development, and people's requirements for spiritual and material enjoyment, serve for commodity economy and beautify people's life.

\section{REFERENCES}

[1] Guo Shan, Tan Manling, Packaging Design [M], Hefei University of Technology Publishing House, 2005: 45-46

[2] Yang Renmin, Packaging Design [M], Chongqing: Southwest China Normal University Press, 1996: 71-73

[3] Jin Bin, Packaging Design [M], Zhejiang Fine Arts Publishing House, 1997: 103-107

[4] Cao Fang, Packaging Design Practice [M], Jiangsu Fine Arts Publishing House, 2005: 94-99

[5] Chen Lei, Step into the World of Packaging Design [M], China Light Industry Press, 2002: 184-188

[6] Zeng Xiankai, Visual Communication Design [M], Beijing Institute of Technology Press, 1991: 63-65 